\title{
Stress and Alterations in the Pain Matrix: A Biopsychosocial Perspective on Back Pain and Its Prevention and Treatment
}

\author{
Pia-Maria Wippert ${ }^{1,2, *}$ and Christine Wiebking ${ }^{1,3}$ \\ 1 Sociology of Health and Physical Activity, Department of Health Science, University of Potsdam, \\ Am Neuen Palais 10, House 12, 14469 Potsdam, Germany; christine.wiebking@uni-ulm.de \\ 2 Department of Health Sciences and Technology, ETH Zürich, HCP, Leopold-Ruzicka-Weg 4, \\ CH-8093 Zürich, Switzerland \\ 3 Institute of Psychology and Education, Applied Emotion and Motivation Research, Ulm University, \\ 89081 Ulm, Germany \\ * Correspondence: wippert@uni-potsdam.de; Tel.: +49-331-977-1051
}

Received: 22 February 2018; Accepted: 9 April 2018; Published: 18 April 2018

\begin{abstract}
The genesis of chronic pain is explained by a biopsychosocial model. It hypothesizes an interdependency between environmental and genetic factors provoking aberrant long-term changes in biological and psychological regulatory systems. Physiological effects of psychological and physical stressors may play a crucial role in these maladaptive processes. Specifically, long-term demands on the stress response system may moderate central pain processing and influence descending serotonergic and noradrenergic signals from the brainstem, regulating nociceptive processing at the spinal level. However, the underlying mechanisms of this pathophysiological interplay still remain unclear. This paper aims to shed light on possible pathways between physical (exercise) and psychological stress and the potential neurobiological consequences in the genesis and treatment of chronic pain, highlighting evolving concepts and promising research directions in the treatment of chronic pain. Two treatment forms (exercise and mindfulness-based stress reduction as exemplary therapies), their interaction, and the dose-response will be discussed in more detail, which might pave the way to a better understanding of alterations in the pain matrix and help to develop future prevention and therapeutic concepts.
\end{abstract}

Keywords: stress; allostatic load; relaxation; back pain; chronic pain; physical activity; exercise; neuroplasticity; pain matrix

\section{Introduction}

Chronic pain is one of the most disabling health complaints, with the highest disability rate worldwide [1]. The majority of these complaints are caused by back pain and arthritis [2]. Given the fact that low back pain (LBP) has a high lifetime prevalence (84\%) and there is a significant risk of subsequent chronification after the first onset of the disease [2-4], research into the underlying mechanisms of these types of chronic pain is of significant interest. Similarly, sophisticated risk assessments, effective prevention strategies, and therapeutic treatments need to be developed to minimize the need for healthcare and the consequent societal economic burden. In line with the multifaceted character of chronic pain, these concepts need to consider musculoskeletal, neuronal, psychobiological, and etiological factors. On the one hand, pain symptoms may be associated with pre-existing vulnerabilities and structural pathologies. On the other hand, functional and/or physical difficulties can be triggered by psychosocial and psychophysiological factors such as stress [5]. 
Therefore, the objective of this paper is to raise a discussion of probable interacting pathways between physical stress (here defined as PS, i.e., exercise), psychological stress (here defined as MS, i.e., mental stress) and their potential neurobiological consequences in the genesis and treatment of chronic pain. In order to focus on treatment interventions that are easy to learn, inexpensive, and can be integrated in everyday life, two therapy forms-namely physical exercise and mindfulness-based stress reduction-and their interaction and dose-response will be considered in more detail.

\section{Neurobiological Consequences of Pain}

Chronic pain is associated with diverse symptoms and severity, and both functional and structural changes in the central nervous system (CNS) as observed in recent neuroimaging studies (see Figure 1). Pain signals are processed in different brain regions and affect various brain networks, and the term "pain matrix" has been established to describe three major systems commonly affected by pain signals: the lateral and the medial system as the two main afferent pain pathways, and the descending system involved in pain perception [6,7]. Due to the vast efferent and afferent connections of thalamic nuclei it was assumed that chronic back pain patients may show alterations in these subcortical areas.

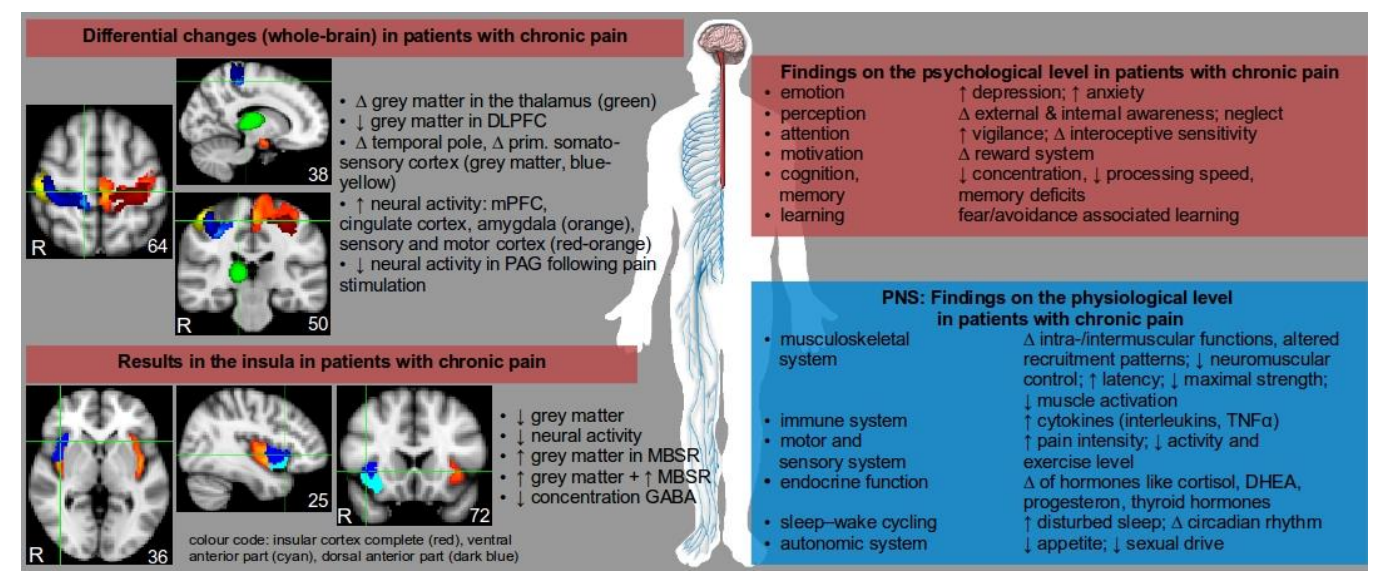

Figure 1. Overview of the complex and multidimensional changes in the central (red area) and peripheral nervous system (PNS, blue area) in patients with chronic pain. $\uparrow$ increased, $\downarrow$ decreased, $\Delta$ change, + positive relation. Abbreviations: ACTH $=$ adrenocorticotropic hormone, DHEA = dehydroepiandrosterone, GABA $=\gamma$-aminobutyric acid, MBSR $=$ mindfulness-based stress reduction, $\mathrm{PAG}=$ periaqueductal grey, $\mathrm{PFC}=$ prefrontal cortex, $\mathrm{TNF}=$ tumor necrosis factor. The content of the picture is not exhaustive, but serves to demonstrate the complexity of chronic pain by listing relevant consequences, cofactors, and epiphenomena. Brain regions displayed on MNI template.

Using structural magnetic resonance imaging (sMRI) to investigate structural changes in the brains of chronic back pain patients provided inconsistent results. Contradictory findings revealed both an increase [8] and a decrease [9] of grey matter volume in the thalamus of chronic back pain patients. However, two studies reported a reduction of grey matter volume in the dorsolateral prefrontal cortex (DLPFC), though other MRI results indicated opposite findings. A recent meta-analysis [10] confirmed structural changes in chronic back pain patients, particularly in the dorsolateral prefrontal cortex (DLPFC), temporal lobe, the insular cortex, and the primary somatosensory cortex (see also the paper by Baliki et al. [11]). Variations in the white matter between patients with chronic back pain and controls have been investigated less frequently, which makes drawing a conclusion about neurobiological structural changes in these populations difficult at the present time. In the future, methodological imaging problems like the influence of pain medication (such as analgesic drugs and antidepressants) on blood flow and pressure need to be considered, as these factors may have a substantial impact on blood-oxygen level dependent signals [12]. 
In contrast to the quantification of grey matter changes investigated by sMRI, results of neuroimaging studies using resting-state functional MRI (rsfMRI) in chronic back pain patients show more consistent results. Increased neural activity in chronic pain patients during resting-state fMRI was reported in various cortical brain regions such as the medial prefrontal cortex (MPFC), cingulate cortex, or the insular cortex, as well as in subcortical brain regions like the amygdala [13]. In addition, sensory and motor cortex areas, which play a major role in pain perception and chronification processes, showed increased neural activity and connectivity to other areas of the brain (see Figure 1). It can further be assumed that a causal relationship exists between cortico-striatal connectivity and pain persistence [11]. Compared to studies using resting-state fMRI, there are few studies investigating neural changes in chronic back pain patients using stimulus-induced fMRI; that is, during the application of painful pressure stimuli. Stimulus-induced fMRI studies in chronic pain patients are difficult to conduct due to ethical concerns and movement-related artefacts in fMRI analysis. Moreover, such neuroimaging studies differ in terms of patient population (chronic back pain, fibromyalgia, rheumatism, etc.), applied stimuli (electrical shock, heat stimuli, pressure, etc.), location of applied stimuli (fingernail, forearm, abdomen, etc.), intensity of applied pain (ranging from unexpected versus expected and/or ambiguous light pain to intense pain), imaging methods (fMRI, sMRI, rsfMRI, electroencephalography, etc.) and analysis techniques (voxel-based morphometry, multivariate pattern analysis, functional connectivity, regional homogeneity, etc.). Despite these multiple approaches each characterized by certain advantages and disadvantages, several results indicate a rather consistent pattern of neural activity relating to pain: increased activity in the somatosensory cortex and the insular cortex after painful stimulation. However, patients with chronic back pain showed decreased neural activity after painful stimulation in the periaquaductal grey [14]. Since the insular cortex plays a central role in physiological regulation processes, body-related focused attention, and pain processing, differences in neural activity, connectivity, and structural changes might play a role when considering the potential of therapies like mindfulness-based stress reduction (MBSR, see Figure 1, e.g., Paulus' research [15]), amongst other psychological and cognitive-behavioral approaches.

The reported neurobiological alterations in the imaging studies are based on prolonged sensitization processes in the peripheral and central pain processing components of the CNS. Whilst acute pain stimuli in the periphery lead to activation of nociceptors on peripheral nerve fibres, processed by mechano-, chemo- or thermo-receptors, different types of peripheral and central neurotransmitters such as serotonin, the substance $\mathrm{P}$, histamine, and prostaglandins are involved in signal transmission. These neurochemical mediators interact with each other and can trigger reorganization processes in nociceptors, such as increased recruitment of receptors and sensitization towards painful stimuli. Finally, modulatory changes constitute increased afferent activity to a given painful stimulus due to inflammation being present, a phenomenon called primary hyperalgesia [16]. Prolonged abnormal afferent information from pain receptors is relayed to the spinal cord (via neurons of the first lamina of the posterior grey horns) and transferred to supraspinal brain areas. Amongst others, ascending pain pathways project to the reticular formation in the brainstem (involved in somatic motor and cardiovascular control and pain modulation), the limbic system (including the anterior cingulate cortex; this system is involved in affective-cognitive aspects of pain including anxiety, emotion, and memory) and the somatosensory cortex (determination of location, intensity, and duration of painful stimuli). Conversely, these brain areas influence descending antinociceptive pathways by modulating descending serotonergic and noradrenergic signals from the brainstem that regulate nociceptive processing at the spinal level. Thus, spinal sensitivity in response to peripheral pain stimuli is modulated by a complex network of inhibitory and excitatory spinal and brain circuits, linking the modulation of the descending system to the level of cord sensitivity in a behavioural and environmental context. For example, the experience of excessive and prolonged physical pain can cause feelings of anxiety and sleep deficits, and-as a result of this reciprocal regulation-the sensation of pain becomes more intense [16]. 
Taken together, the long-term increase in pain sensitivity is associated with abnormal signal transmissions within the spinal cord and changes in the descending pathway involved in the regulation of pain. The resulting hyperexcitability to stimuli can occur at both the peripheral and central level; for example, minor peripheral signals may evoke a severe experience of pain if the self-reinforcing mechanism (so-called "wind-up") is established centrally.

Although this reciprocal pain regulation is well-documented [16], our knowledge about the genesis of chronic pain syndromes and effective treatments is still limited. Whereas pharmaceutical approaches promote solutions within the scope of inhibitor identification (e.g., steroids/nonsteroidal anti-inflammatory drugs (NSAIDs), serotonin or noradrenaline reuptake inhibitors (SSRIs, SNRIs), etc.), the behavioural and exercise sciences investigate the effects of conditioning principles and adaptation. From this point of view, the experience and perception of pain, including regulatory pain mechanisms, may go well beyond neural networks, nerve cells, and neurochemical factors. Various other factors need to be considered in the framework of chronic pain as it is moderated by age, gender, psychosocial factors, lifestyle conditions, and genetic predispositions [16].

\section{Neurobiological Consequences of Physical Stress (PS) Such as Exercise}

\subsection{Adaptation to Exercise in the Prevention of Chronic Pain}

Neural plasticity of the nervous system is essential in order to accomplish neurobiological adaption to physical activity and exercise, which are important players in the prevention of chronic pain. The central nervous system is responsible for a stable foundation of extremity movements, co-contraction of particular muscles, appropriate muscle recruitment, and the adaptability and timing needed for core stability [17]. Altered muscular interaction schemes or altered afferent combinations, such as inhibition or aberrant innervation of individual muscles, dramatically affect spinal statics, movement execution, and spatial constancy mechanisms. Furthermore, altered phasic sequences of synergistic muscle activations can affect the stability of trunk and limb movements. This can be compensated for by motor control exercises for trunk muscles aimed at improving stability, mobility, intra and intermuscular function, and innervation patterns. However, the general advantage of exercise may additionally be based on neuroplastic central effects. This applies to central pain-processing areas and induces changes in cell growth, vascularization, and morphologic alterations of grey matter [18-20]. These intended positive exercise effects may prohibit the described pain-induced maladaptive changes in brain structures (see Section 2). Another interesting effect of most types of exercise is a reduction of pain perception following acute exercise, a phenomenon known as exercise-induced hypoalgesia (EIH) [21,22]. Although there is evidence that exercise induces a higher pain tolerance [23], the appropriate exercise dose for an optimal EIH response is still unknown [24,25]. This lack of knowledge limits the systematic application of the EIH effect to therapy programs [22] despite it being proven as effective in some studies [26]. Further, the mechanisms of EIH are not fully understood; on the one hand, study results imply that exercise may be related to a reduced endogenic pain inhibition system caused by altered processing of somatosensory stimuli [27]. On the other hand, some studies suggest an involvement of opioid and non-opioid mechanisms [21,28]. However, both of the main effects of exercise (central and peripheral) affect the reciprocal regulation sides in the genesis of chronic pain and may be useful in preventive strategies (see Section 2).

It is particularly important to emphasize that low back pain patients show a variety of central and peripheral maladaptations: studies report inadequate constancy, altered neuromuscular activity, and reduced neuromuscular control function as well as increased latency and reduced activation under physical stress and perturbation $[17,29]$. Further, the ability to engage maximum strength and endurance, essential for the compensation of high loads, is also impaired [30]. 


\subsection{Adaptation to Exercise in Therapy}

Exercises of the trunk muscles are involved in state-of-the-art treatments in the prevention and therapy of low back pain [31,32]. Motor control exercises (sensory-motor training, or SMT), including balancing and strengthening elements, are especially appropriate for improvement in neuromuscular control, strength, and kinematics of the trunk muscles and spine balance during changing mechanical disruptions. However, reviews show that sensory-motor training [33] or other exercises types [34] are not inevitably related to a prolonged pain or disability reduction. An adequate explanation for this has not yet been found.

The search for an exercise treatment that effectively reduces pain symptoms leads to a discussion about the specificity [33], intensity, and dose of an offered exercise [35] that may regulate the dose-response relationship of the pain experience in the individual [22]. Considering the "wind-up" (mechanism of sensitization and reciprocal regulation of pain stimuli, see Section 2), two scenarios can be considered: Firstly, exercises executed at high intensity may induce the activation of afferent pain receptors (located in skin, muscles, and bones). Thus, peripheral sensitization might be further provoked by excessive mechanical load or pre-existing functional deficits. Imaging studies investigating stimulus-induced pain show that peripheral sensitization can be associated with central hypersensitivity, a reduced endogenous pain inhibition [36], and a higher intrinsic activity in the somatosensory cortices with a synchronization of the sensory-motor neural network (SMN) [37]. Secondly, central hypersensitivity in the limbic system, relating to affective-cognitive aspects of pain, influences descending antinociceptive pathways [16]. Depending on the type of exercise (e.g., lacking postural control), anxious feelings, fear of pain, and negative expectations of the exercise treatment may arise, thus resulting in increased pain perception. Both exercise conditions (too intensive/without postural control) would prohibit the intended EIH. To date, the interactions between EIH, fear conditioning, and the dose-response of exercise are still unknown, although they have been raised in proof of concept studies [22,26]. Besides the choice of the right exercise dose, these findings raise a question regarding whether conditioning tasks could affect certain brain areas (such as the limbic system), subsequently interrupting the dysfunctional reciprocal circle, and whether they could therefore be combined with exercise tasks in therapeutic programs.

Evidence from different scientific fields suggests that distraction tasks can be utilized as a deconditioning tool for pain and for disruption of the affective-cognitive mechanisms of fear avoidance to exercise. For example, cognitive distraction is processed in similar cortical networks as the sensory aspects and inhibition of pain (e.g., in the hippocampus, prefrontal cortex, and amygdala [30]) and has been associated with a reduced subjective pain perception in various studies [38]. This is based on the assumption that simultaneous processing of pain signals and cognitive stimuli is limited due to an overlapping and restricted set of mental resources [39]. The desired outcome-reduced subjective pain intensity and increased pleasantness-was observed in several studies, especially for executive memory working tasks (e.g., n-back task [40], Stroop task [41]) or for arithmetic tasks such as the paced auditory serial addition test $[40,42]$. Currently, a combination of SMT exercise and cognitive tasks has been evaluated in proof of concept studies on low back pain [43,44]. These studies aim for a reduction in the subjective pain experience and increased motor amplitude, as well as an improvement in muscle function and strength, following the ideas of new effective treatment forms and prevention tasks.

\section{Neurobiological Consequences of Mental Stress (MS)}

\subsection{Adaptation to Psychosocial Stress}

In addition to physical stress, biological stress responses can also be induced by psychosocial stressors (here defined as mental stress). This response is driven by the autonomic nervous system (ANS), the anterior pituitary glands, and the hypothalamus [45], whereby the stress response within the ANS proceeds to one of three peripheral catecholamine systems with a release of neurotransmitters (i.e., norepinephrine, acetylcholine, dopamine, or cytokines). Within the anterior 
pituitary glands and the hypothalamus, the stress response is driven by synaptic information from different brain regions like the limbic system (including the hippocampus and amygdala) or the brainstem (including the locus coeruleus). The effects of the stress response are reflected across five endocrine axes: the hypothalamic-pituitary-adrenal (HPA), hypothalamic-pituitary-thyroid (HPT), hypothalamic-pituitary-gonadal (HPG), hypothalamic-pituitary-somatotropic (HPS), and hypothalamic-pituitary-prolactin (HPP). The major role of these complex response systems is the maintenance of homeostasis and promoting adaption to external and internal challenges [46]. A repeated (long-term) activation of these regulatory systems can lead to pathological changes and an accumulated biological burden on the body. This so-called allostatic load can affect the function of the hypothalamic-pituitary axes (e.g., HPA hyper or hypofunction), and the immune, cardiovascular, and metabolic systems [47]. During the development of an increased allostatic load, other components from the neuroendocrine and immune system play a role, which in turn are associated with stress-related pain disorders [48].

Considering the sensitization process and reciprocal regulation of pain stimuli ("wind up" mechanism), the following scenarios can be assumed for the association between MS and pain: Firstly, microstructural damage [49], musculoskeletal disorders, and local muscle tension reactions [50] may be stabilized in response to altered neurotransmitter concentrations (inflammatory mediators like cytokines, growth hormones and others, see Figure 1) and their peripheral influence on nociceptor-sensitization, receptor recruitment, and signal transmission to the somatosensory cortex. Thus, maladaptive muscle tension can activate afferent pain fibres in the muscles and bones of neighbouring regions and promote peripheral sensitization processes [51]. Secondly, altered neurotransmitter concentrations in supraspinal brain areas caused by HPA-hypofunction constrain descending antinociceptive pathways by modulation of descending serotonergic and noradrenergic signals from the brainstem, regulating nociceptive processing at the spinal level. Thirdly, a keloid stress response (e.g., HPA-hyperfunction) provokes neurotoxic effects and maladaptations such as limited cell proliferation, volume matter reduction, and re-organisation in brain areas which are involved in pain processing (e.g., the hippocampal area) [47,48]. The adaptation to both chronic stress and to chronic pain can promote changes in the volume of grey matter [47]. Fourthly, an altered metabolic system (such as local lipid storage or the amount of cholesterol in the plasma membrane) can trigger myelination and peripheral nerve function [52] as well as pain transmission [53]. In sum, several stress-associated mechanisms are involved in the human pain response.

\subsection{Adaptation to Relaxation Treatments in Therapy}

In considering relaxation techniques in order to attenuate the aforementioned stress mechanisms, the mindfulness-based stress reduction (MBSR) program—as one stress reduction program amongst others [54] - may be a plausible treatment strategy. This structured therapy program combines elements of meditation, yoga, and physical attention. It aims to encourage the practice of body-related focused attention in daily life situations and supports the acceptance and processing of pain-associated stimuli and even negative emotions.

Its effectiveness in treating chronic pain has been reported in several different studies $[55,56]$ and its effects are comparable to the mean effects of cognitive-behavioral therapy [57]. Regarding the pronounced reciprocal regulation of pain stimuli (see Section 2) it is relevant to note that body-related focused attention is associated with increased neural activity in the insular cortex [58,59]. Furthermore, neural activity during body-related focused attention is associated with concentration of the neurotransmitter GABA in the insular cortex, a region where body-related physiological stimuli including pain stimuli are processed [59] (see Figure 1), amongst other regions in the human brain (anterior cingulate cortex, primary/secondary somatosensory cortices, etc.). In addition, the application of mindfulness meditation was linked to a reduction in fear-avoidance behavior and improved perception of sensory information [60]. 
This supports the ideas of restructuring of volume and of biochemical deteriorations that affect pain patients [61]. Further, MBSR supports the regulation of emotions (e.g., in the medial prefrontal cortex) and can reduce stress and anxiety, which in turn can interfere with the pain response in humans. Persons who are exposed to traumata or high frequency stressors can show a limited stress response on the HPA axis. In this case pain stimuli are not associated with increased intrinsic brain activity, but rather deficient pain inhibition, which in turn is linked to increased pain sensitivity [48].

\section{Interaction between Mental Stress and Physical Stress (MS and PS)}

Having briefly reviewed the individual effects of physical stress (e.g., exercise), mental stress (e.g., psychosocial stress) and the potential neurobiological consequences in the genesis and treatment of chronic pain, it is relevant to look at the interaction of two treatment forms (motor control exercise, mindfulness-based stress reduction) within multimodal programs in more detail. Although the Cochrane reviews report a higher effectiveness of multimodal treatments in comparison to unimodal physical or cognitive-behavioural treatments [34,62-64], it is still unclear if this combination must be oriented to the suggested effects of each treatment form itself.

Numerous studies point out that moderate exercise modulates the activity of the HPA axis, leading to a reduced degree of stress responsiveness, improved ANS regulation, and altered HPA axis function resulting in a reduced allostatic load. More evidence accumulates when considering the positive effects of moderate exercise on brain development (e.g., cell proliferation), as well as the moderation of depressive symptoms, anxiety, and cognitive problems. On the contrary, high intensity exercise does not exert these positive influences; rather, high intensity exercise induces a delayed feedback mechanism in the HPA axis (stopping glucocorticoid release) and the allostatic load increases. Under these conditions, the likelihood of the successful development of an EIH or an acute induced stress analgesia decreases. It is obvious that an interaction between physical and mental stress also affect therapy programs for pain patients.

For example, individuals with a hyperfunction of the HPA axis show increased pain sensitivity during and after a "normal" exercise dose, and reduced pain symptoms only during or after a mild exercise dose. In addition, they show disturbed affect regulation in response to applied pain stimuli [65]. The choice of the most suitable exercise dose must therefore be aligned to the individual's MS status-in this case the HPA function-which can be difficult to achieve. In the current example a multimodal program, starting with MBSR training followed by motor control training, would probably generate the most beneficial effects. The choice of an optimal combination of different treatment forms may be important, but has been completely neglected in recent programs and could serve to explain the reported short-term effects of exercise treatments [33]. However, there is a lack of scientific evidence for such claims, as selection tools for the classification of appropriate exercise intensity or behavioural treatments are still missing. Recently, a novel diagnostic tool was developed which allows a stratified treatment allocation to additional biopsychosocial treatment in combination with exercise treatment [66]. This screening tool identifies MS as well as affective-cognitive aspects of pain (including anxiety and emotion) while respecting the individual physical activity status. As the evidence suggests that these factors may be important to explore further, this tool for individual stratified treatment allocation could be helpful in planning future and optimal treatments.

\section{Conclusions}

This paper discusses possible pathways between physical and mental stress and potential neurobiological consequences in the genesis and treatment of chronic pain. Therapeutically relevant targets, such as pain-related neural maladaptations and pain-related mechanisms between exercise and relaxation techniques, are presented and discussed. By highlighting some evolving concepts, promising research directions in the prevention and treatment of chronic pain may be established. 
Acknowledgments: We acknowledge the support of the Deutsche Forschungsgemeinschaft, the German Federal Institute of Sport Science (MiSpEx grant-number: 080102A/11-14) and the Open Access Publishing Fund of University of Potsdam.

Author Contributions: Pia-Maria Wippert and Christine Wiebking drafted, edited and finalized the manuscript, approved the final version of manuscript and agreed to be accountable for all aspects of the work.

Conflicts of Interest: The authors declare no conflict of interest.

\section{Abbreviations}

$\begin{array}{ll}\text { ANS } & \text { autonomic nervous system } \\ \text { CNS } & \text { central nervous system } \\ \text { DLPFC } & \text { dorsolateral prefrontal cortex } \\ \text { EIH } & \text { Exercise-induces hypoalgesia } \\ \text { fMRI } & \text { functional magnetic resonance imaging } \\ \text { GABA } & \gamma \text {-aminobutyric acid } \\ \text { HPA } & \text { hypothalamic-pituitary-adrenal axis } \\ \text { HPG } & \text { hypothalamic-pituitary-gonadal axis } \\ \text { HPP } & \text { hypothalamic-pituitary-prolactin axis } \\ \text { HPS } & \text { hypothalamic-pituitary-somatotropic axis } \\ \text { HPT } & \text { hypo-thalamic-pituitary-thyroid axis } \\ \text { LBP } & \text { low back pain } \\ \text { CLBP } & \text { chronic low back pain } \\ \text { MBSR } & \text { mindfulness-based stress reduction program } \\ \text { MPFC } & \text { medial prefrontal cortex } \\ \text { MS } & \text { mental stress } \\ \text { PS } & \text { physical stress } \\ \text { rsfMRI } & \text { resting-state functional magnetic resonance imaging } \\ \text { SMN } & \text { sensory-motor neural network } \\ \text { sMRI } & \text { structural magnetic resonance imaging } \\ \text { SMT } & \text { sensory-motor training } \\ \text { SNRIs } & \text { selective noradrenaline reuptake inhibitors } \\ \text { SSRIs } & \text { selective serotonin reuptake inhibitors } \\ \text { NSAIDs } & \text { nonsteroidal anti-inflammatory drugs } \\ & \end{array}$

\section{References}

1. Vos, T.; Barber, R.M.; Bell, B.; Bertozzi-Villa, A.; Biryukov, S.; Bolliger, I.; Charlson, F.; Davis, A.; Degenhardt, L.; Dicker, D.; et al. Global, regional, and national incidence, prevalence, and years lived with disability for 301 acute and chronic diseases and injuries in 188 countries, 1990-2013: A systematic analysis for the Global Burden of Disease Study 2013. Lancet 2015, 386, 743-800. [CrossRef]

2. Henschke, N.; Kamper, S.J.; Maher, C.G. The epidemiology and economic consequences of pain. Mayo Clin. Proc. 2015, 90, 139-147. [CrossRef] [PubMed]

3. Hoy, D.; Brooks, P.; Blyth, F.; Buchbinder, R. The epidemiology of low back pain. Best Pract. Res. Clin. Rheumatol. 2010, 24, 769-781. [CrossRef] [PubMed]

4. Taylor, J.B.; Goode, A.P.; George, S.Z.; Cook, C.E. Incidence and risk factors for first-time incident low back pain: A systematic review and meta-analysis. Spine J. 2014, 14, 2299-2319. [CrossRef] [PubMed]

5. Diatchenko, L.; Nackley, A.G.; Slade, G.D.; Fillingim, R.B.; Maixner, W. Idiopathic pain disorders-pathways of vulnerability. Pain 2006, 123, 226-230. [CrossRef] [PubMed]

6. Henry, D.E.; Chiodo, A.E.; Wang, W. Central nervous system reorganization in a variety of chronic pain states: A review. PMR 2011, 3, 1116-1125.

7. Fabbro, F.; Crescentini, C. Facing the experience of pain: A neuropsychological perspective. Phys. Life Rev. 2014, 11, 540-542. [CrossRef] [PubMed]

8. Schmidt-Wilcke, T.; Leinisch, E.; Gänssbauer, S.; Draganski, B.; Bogdahn, U.; Altmeppen, J.; May, A. Affective components and intensity of pain correlate with structural differences in gray matter in chronic back pain patients. Pain 2006, 125, 89-97. [CrossRef] [PubMed] 
9. Apkarian, A.V.; Sosa, Y.; Sonty, S.; Levy, R.M.; Harden, R.N.; Parrish, T.B.; Gitelman, D.R. Chronic back pain is associated with decreased prefrontal and thalamic gray matter density. J. Neurosci. 2004, 24, 10410-10415. [CrossRef] [PubMed]

10. Kregel, J.; Meeus, M.; Malfliet, A.; Dolphens, M.; Danneels, L.; Nijs, J.; Cagnie, B. Structural and functional brain abnormalities in chronic low back pain: A systematic review. Semin. Arthritis Rheum. 2015, 45, 229-237. [CrossRef] [PubMed]

11. Baliki, M.N.; Petre, B.; Torbey, S.; Herrmann, K.M.; Huang, L.; Schnitzer, T.J.; Fields, H.L.; Apkarian, A.V. Corticostriatal functional connectivity predicts transition to chronic back pain. Nat. Neurosci. 2012, 15, 1117-1119. [CrossRef] [PubMed]

12. Franklin, T.R.; Wetherill, R.R.; Jagannathan, K.; Hager, N.; O'Brien, C.P.; Childress, A.R. Limitations of the use of the MP-RAGE to identify neural changes in the brain: Recent cigarette smoking alters gray matter indices in the striatum. Front. Hum. Neurosci. 2014, 8, 1052. [CrossRef] [PubMed]

13. Baliki, M.N.; Geha, P.Y.; Apkarian, A.V.; Chialvo, D.R. Beyond feeling: Chronic pain hurts the brain, disrupting the default-mode network dynamics. J. Neurosci. 2008, 28, 1398-1403. [CrossRef] [PubMed]

14. Giesecke, T.; Gracely, R.H.; Grant, M.A.; Nachemson, A.; Petzke, F.; Williams, D.A.; Clauw, D.J. Evidence of augmented central pain processing in idiopathic chronic low back pain. Arthritis Rheum. 2004, 50, 613-623. [CrossRef] [PubMed]

15. Paulus, M.P. Neural basis of mindfulness interventions that moderate the impact of stress on the brain. Neuropsychopharmacology 2016, 41, 373. [CrossRef] [PubMed]

16. Harvey, V.; Dickenson, A. Neurobiology of pain. In Evidence-Based Chronic Pain Management; Stannard, C., Kalso, E., Ballantyne, J., Eds.; Wiley-Blackwell: Oxford, UK, 2010; pp. 42-51.

17. Borghuis, J.A.; Hof, L.; Lemmink, K.A. The importance of sensory-motor control in providing core stability: Implications for measurement and training. Sports Med. 2008, 38, 893-916. [CrossRef] [PubMed]

18. Burciu, R.G.; Fritsche, N.; Granert, O.; Schmitz, L.; Spönemann, N.; Konczak, J.; Theyson, N.; Gerwig, M.; van Eimeren, T.; Timmann, D. Brain changes associated with postural training in patients with cerebellar degeneration: A voxel-based morphometry study. J. Neurosci. 2013, 33, 4594-4604. [CrossRef] [PubMed]

19. Vivar, C.; Potter, M.C.; van Praag, H. All about running: Synaptic plasticity, growth factors and adult hippocampal neurogenesis. Curr. Top. Behav. Neurosci. 2013, 15, 189-210. [PubMed]

20. Erickson, K.I.; Gildengers, A.G.; Butters, M.A. Physical activity and brain plasticity in late adulthood. Dial. Clin. Neurosci. 2013, 15, 99-108.

21. Hoeger-Bement, M.K. Exercise-induced hypoalgesia: An evidenced-based review. In Management and Mechanisms of Pain for the Physical Therapist; Bement, M.K.H., Sluka, K.A., Eds.; Wolters Kluwer: Alphen aan den Rijn, The Netherlands, 2009.

22. Naugle, K.M.; Fillingim, R.B.; Riley, J.L. A meta-analytic review of the hypoalgesic effects of exercise. J. Pain 2012, 13, 1139-1150. [CrossRef] [PubMed]

23. Tesarz, J.; Schuster, A.K.; Hartmann, M.; Gerhardt, A.; Eich, W. Pain perception in athletes compared to normally active controls: A systematic review with meta-analysis. Pain 2012, 153, 1253-1262. [CrossRef] [PubMed]

24. Naugle, K.M.; Naugle, K.E.; Fillingim, R.B.; Samuels, B.; Riley, J.L. Intensity thresholds for aerobic exercise-induced hypoalgesia. Med. Sci. Sports Exerc. 2014, 46, 817-825. [CrossRef] [PubMed]

25. Koltyn, K.F. Exercise-induced hypoalgesia and intensity of exercise. Sports Med. 2012, 32, 477-487. [CrossRef]

26. O'Leary, S.; Falla, D.; Hodges, P.W. Specific therapeutic exercise of the neck induces immediate local hypoalgesia. J. Pain 2007, 8, 832-839. [CrossRef] [PubMed]

27. Tesarz, J.; Gerhardt, A.; Schommer, K.; Treede, R.D.; Eich, W. Alterations in endogenous pain modulation in endurance athletes: An experimental study using quantitative sensory testing and the cold-pressor task. Pain 2013, 154, 1022-1029. [CrossRef] [PubMed]

28. Koltyn, K.F.; Brellenthin, A.G.; Cook, D.B.; Sehgal, N.; Hillard, C. Mechanisms of exercise-induced hypoalgesia. J. Pain 2014, 15, 1294-1304. [CrossRef] [PubMed]

29. Radebold, A.; Cholewicki, J.; Panjabi, M.M.; Patel, T.C. Muscle response pattern to sudden trunk loading in healthy individuals and in patients with chronic low back pain. Spine (Phila Pa 1976) 2000, 25, 947-954.

[CrossRef] 
30. Bayramoglu, M.; Akman, M.N.; Klnç, S.; Çetin, N.; Yavuz, N.; Özker, R. Isokinetic measurement of trunk muscle strength in women with chronic low-back pain. Am. J. Phys. Med. Rehabil. 2001, 80, 650-655. [CrossRef] [PubMed]

31. Standaert, C.J.; Weinstein, S.M.; Rumpeltes, J. Evidence-informed management of chronic low back pain with lumbar stabilization exercises. Spine J. 2008, 8, 114-120. [CrossRef] [PubMed]

32. Hayden, J.A.; Van Tulder, M.W.; Tomlinson, G. Systematic review: Strategies for using exercise therapy to improve outcomes in chronic low back pain. Ann. Intern. Med. 2005, 142, 776-785. [CrossRef] [PubMed]

33. Saragiotto, B.T.; Maher, C.G.; Yamato, T.P.; Costa, L.O.; Costa, L.C.; Ostelo, R.W.; Macedo, L.G. Motor control exercise for chronic non-specific low back pain. Cochrane Database Syst. Rev. 2016, 1. [CrossRef] [PubMed]

34. Hayden, J.A.; van Tulder, M.W.; Malmivaara, A.; Koes, B.W. Exercise therapy for treatment of non-specific low back pain. Cochrane Database Syst. Rev. 2005, 1, CD000335. [CrossRef] [PubMed]

35. Chou, R.; Shekelle, P. Will this patient develop persistent disabling low back pain? JAMA 2010, 303, 1295-1302. [CrossRef] [PubMed]

36. Edwards, R.R. Individual differences in endogenous pain modulation as a risk factor for chronic pain. Neurology 2005, 65, 437-443. [CrossRef] [PubMed]

37. Riedl, V.; Valet, M.; Wöller, A.; Sorg, C.; Vogel, D.; Sprenger, T.; Boecker, H.; Wohlschläger, A.M.; Tölle, T. Repeated pain induces adaptations of intrinsic brain activity to reflect past and predict future pain. Neuroimage 2011, 57, 206-213. [CrossRef] [PubMed]

38. McEwen, B.S.; Nasveld, P.; Palmer, M.; Anderson, R. Allostatic Load: A Review of the Literature; Department of Veterans' Affairs: Canberra, Australia, 2012.

39. Buhle, J.T.; Stevens, B.L.; Friedman, J.J.; Wager, T.D. Distraction and placebo two separate routes to pain control. Psychol. Sci. 2012, 23, 246-253. [CrossRef] [PubMed]

40. Villemure, C.; Bushnell, M.C. Mood influences supraspinal pain processing separately from attention. J. Neurosci. 2009, 29, 705-715. [CrossRef] [PubMed]

41. Valet, M.; Sprenger, T.; Boecker, H.; Willoch, F.; Rummeny, E.; Conrad, B.; Erhard, P.; Tolle, T.R. Distraction modulates connectivity of the cingulo-frontal cortex and the midbrain during pain-An fmri analysis. Pain 2004, 109, 399-408. [CrossRef] [PubMed]

42. Villarreal, E.A.G.; Brattico, E.; Vase, L.; Østergaard, L.; Vuust, P. Superior analgesic effect of an active distraction versus pleasant unfamiliar sounds and music: The influence of emotion and cognitive style. PLoS ONE 2012, 7, e29397. [CrossRef] [PubMed]

43. Wippert, P.M.; de Witt Huberts, J.; Klipker, K.; Gantz, S.; Schiltenwolf, M.; Mayer, F. Beschreibung und empirische fundierung des verhaltenstherapeutischen moduls der MiSpEx-intervention. Der Schmerz 2015, 29, 658-663. [CrossRef] [PubMed]

44. Niederer, D.; Vogt, L.; Wippert, P.M.; Puschmann, A.K.; Pfeifer, A.C.; Schiltenwolf, M.; Banzer, W.; Mayer, F. Medicine in spine exercise (MiSpEx) for nonspecific low back pain patients: Study protocol for a multicentre, single-blind randomized controlled trial. Trials 2016, 17, 507. [CrossRef] [PubMed]

45. Wippert, P.M.; Rector, M.; Kuhn, G.; Wuertz-Kozak, K. Stress and alterations in bones: An interdisciplinary perspective. Front. Endocrinol. 2017, 8, 96. [CrossRef] [PubMed]

46. McEwen, B.S.; Wingfield, J.C. The concept of allostasis in biology and biomedicine. Horm. Behav. 2003, 43, 2-15. [CrossRef]

47. McEwen, B.S. Physiology and neurobiology of stress and adaptation: Central role of the brain. Physiol. Rev. 2007, 87, 873-904. [CrossRef] [PubMed]

48. McEwen, B.S.; Kalia, M. The role of corticosteroids and stress in chronic pain conditions. Metabolism 2010, 59, 9-15. [CrossRef] [PubMed]

49. Jiao, K.; Niu, L.; Xu, X.; Liu, Y.; Li, X.; Tay, F.R.; Wang, H. Norepinephrine regulates condylar bone loss via comorbid factors. J. Dent. Res. 2015, 94, 813-820. [CrossRef] [PubMed]

50. Generaal, E.; Vogelzangs, N.; Macfarlane, G.J.; Geenen, R.; Smit, J.H.; Penninx, B.W.; Dekker, J. Reduced hypothalamic-pituitary-adrenal axis activity in chronic multi-site musculoskeletal pain: Partly masked by depressive and anxiety disorders. BMC Musculoskelet. Disord. 2014, 15, 227. [CrossRef] [PubMed]

51. Van Houdenhove, B.; Luyten, P. Beyond dualism: The role of life stress in chronic pain. Pain 2005, 113, 238-247. [CrossRef] [PubMed]

52. Verheijen, M.; Chrast, R.; Burrola, P.; Lemke, G. Local regulation of fat metabolism in peripheral nerves. Genes Dev. 2003, 17, 2450-2464. [CrossRef] [PubMed] 
53. Amsalem, M.; Poilbout, C.; Ferracci, G.; Delmas, P.; Padilla, F. Membrane cholesterol depletion as a trigger of Nav1.9 channel-mediated inflammatory pain. EMBO J. 2018, 37, e97349. [CrossRef] [PubMed]

54. Goyal, M.; Singh, S.; Sibinga, E.M.S.; Gould, N.F.; Rowland-Seymour, A.; Sharma, R.; Berger, Z.; Sleicher, D.; Maron, D.D.; Shihab, H.M.; et al. Meditation programs for psychological stress and well-being-A systematic review and meta-analysis. JAMA Intern. Med. 2014, 174, 357-368. [CrossRef] [PubMed]

55. Marchand, W.R. Mindfulness-based stress reduction, mindfulness-based cognitive therapy, and zen meditation for depression, anxiety, pain, and psychological distress. J. Psychiatr. Pract. 2012, 18, $233-252$. [CrossRef] [PubMed]

56. Morone, N.E.; Greco, C.M.; Weiner, D.K. Mindfulness meditation for the treatment of chronic low back pain in older adults: A randomized controlled pilot study. Pain 2008, 134, 310-319. [CrossRef] [PubMed]

57. Veehof, M.M.; Oskam, M.J.; Schreurs, K.M.; Bohlmeijer, E.T. Acceptance-based interventions for the treatment of chronic pain: A systematic review and meta-analysis. Pain 2011, 152, 533-542. [CrossRef] [PubMed]

58. Critchley, H.D.; Wiens, S.; Rotshtein, P.; Öhman, A.; Dolan, R.J. Neural systems supporting interoceptive awareness. Neural Syst. Support. Interoceptive Awareness 2004, 7, 189-195. [CrossRef] [PubMed]

59. Wiebking, C.; Duncan, N.W.; Tiret, B.; Hayes, D.J.; Marjaǹska, M.; Doyon, J.; Bajbouj, M.; Northoff, G. Gaba in the insula-A predictor of the neural response to interoceptive awareness. Neuroimage 2014, 86, 10-18. [CrossRef] [PubMed]

60. Zeidan, F.; Grant, J.A.; Brown, C.A.; McHaffie, J.G.; Coghill, R.C. Mindfulness meditation-related pain relief: Evidence for unique brain mechanisms in the regulation of pain. Neurosci. Lett. 2012, 520, 165-173. [CrossRef] [PubMed]

61. Villemure, C.; Čeko, M.; Cotton, V.A.; Bushnell, M.C. Insular cortex mediates increased pain tolerance in yoga practitioners. Cereb. Cortex 2013, 24, 2732-2740. [CrossRef] [PubMed]

62. Henschke, N.; Ostelo, R.W.; van Tulder, M.W.; Vlaeyen, J.W.; Morley, S.; Assendelft, W.J.; Main, C.J. Behavioural treatment for chronic low-back pain. Cochrane Database Syst. Rev. 2010, 7, CD002014. [CrossRef] [PubMed]

63. Engers, A.J.; Jellema, P.; Wensing, M.; van der Windt, D.A.; Grol, R.; van Tulder, M.W. Individual patient education for low back pain. Cochrane Database Syst. Rev. 2008, 1, CD004057. [CrossRef] [PubMed]

64. Heymans, M.W.; Van Tulder, M.W.; Esmail, R.; Bombardier, C.; Koes, B.W. Back schools for nonspecific low back pain. Cochrane Database Syst. Rev. 2004, 8, CD011674. [CrossRef]

65. Cook, D.B.; Stegner, A.J.; Ellingson, L.D. Exercise alters pain sensitivity in Gulf War veterans with chronic musculoskeletal pain. J. Pain 2010, 11, 764-772. [CrossRef] [PubMed]

66. Wippert, P.M.; Puschmann, A.K.; Drießlein, D.; Arampatzis, A.; Banzer, W.; Beck, H.; Schiltenwolf, M.; Schmidt, H.; Schneider, C.; Mayer, F. Development of a risk stratification and prevention index for stratified care in chronic low back pain. Focus: Yellow flags (MiSpEx network). Pain Rep. 2017, 2, e623. [CrossRef] [PubMed]

(C) 2018 by the authors. Licensee MDPI, Basel, Switzerland. This article is an open access article distributed under the terms and conditions of the Creative Commons Attribution (CC BY) license (http://creativecommons.org/licenses/by/4.0/). 